\title{
Adrenal Insufficiency in Cardiogenic Shock: Incidence and Prognostic Implication
}

\author{
Emad Omer, Hanan Zaghla \\ Critical Care Medicine Department, Faculty of Medicine, Cairo University, Giza, Egypt \\ Email: hananzaghla@hotmail.com
}

How to cite this paper: Omer, E. and Zaghla, H. (2019) Adrenal Insufficiency in Cardiogenic Shock: Incidence and Prognostic Implication. World Journal of Cardiovascular Diseases, 9, 562-571. https://doi.org/10.4236/wjcd.2019.98049

Received: July 3, 2019

Accepted: August 16, 2019

Published: August 19, 2019

Copyright $\odot 2019$ by author(s) and Scientific Research Publishing Inc. This work is licensed under the Creative Commons Attribution International License (CC BY 4.0).

http://creativecommons.org/licenses/by/4.0/

\section{(c) (i) Open Access}

\begin{abstract}
Introduction: Functional integrity of the hypothalamic pituitary axis is disrupted during severe infection or stress. The observed blunted response to corticotropin was interpreted as impaired secretory reserve of the adrenal glands and was termed as relative adrenocortical insufficiency. Aim of the work: To study the incidence of adrenal insufficiency in patients developed cardiogenic shock complicating ST segment elevation myocardial infarction. Materials and methods: Prospective cohort study was done for 90 patients admitted to Algalaa Hospital for whom basal cortisol and ACTH level were measured immediately before a standard-dose $(250 \mu \mathrm{g})$ ACTH stimulation test (SST) and 60 minutes after SST $\Delta$ max is defined as the difference between the maximal value after the test and basal level of serum cortisol. Results: Baseline ACTH and total cortisol showed positive correlation to clinical severity scores (APACHE II and Lactate), LVEF as well as vasoactive inotrope score, all with significant $\mathrm{p}$ value $(0.000)$. The higher baseline cortisol level was co-related to increased mortality (Baseline serum cortisol level was significantly lower in survivors ( $30.6 \pm 6.1$ vs $45.0 \pm 16.3) \mathrm{p}$ value: 0.000$)$ while the better response of the adrenal gland to short stimulation test was co-related more to survival as detected by $\Delta \max T C$ (difference of cortisol level before and after SST) $(13.8 \pm 3.8$ in survivors vs $8.5 \pm 4.42$ in non survivors) $\mathrm{p}$ value 0.000 . Conclusion: A high baseline plasma TC was associated with increased mortality in patients with cardiogenic shock post acute myocardial infarction. Patients with lower baseline TC, but with a better adrenal response, appeared to have a survival benefit.
\end{abstract}

\section{Keywords}

Adrenal Insufficiency, Cardiogenic Shock, Myocardial Infarction, Short Stimulation Test, Cortisol, ACTH 


\section{Introduction}

The concept of Relative Adrenal Insufficiency (RAI) in critical illness is still a matter of debate. In a common study published by Boonen et al., it was demonstrated that cortisol clearance is declined to $40 \%$ in critically ill patients with hyperlactatemia and 34 points APACHE II score. The decreased clearance was deemed responsible for the elevated cortisol levels frequently found in critical illness and the lower cortisol clearance was also associated with less cortisol response to corticotropin [1]. Although high cortisol levels appear to argue against a syndrome of corticosteroid insufficiency, the combination of high serum cortisol levels and a blunted response to corticotropin showed the worst prognosis in septic shock [2]. Despite these new insights into cortisol metabolism during critical illness, the prognostic value of a short corticotropin test has been demonstrated in many studies in septic shock, it should be further studied in other types of shock like cardiogenic shock.

AIM of the work: was to study the incidence of relative adrenal insufficiency in patients with cardiogenic shock following acute myocardial infarction and its effect on the prognosis.

\section{Materials and Methods}

This was a prospective observational cohort study where 90 patients (age more than 18 years) were admitted to Algalaa and Kasralainy hospitals from January 2018 to January 2019 fulfilled the diagnostic criteria of cardiogenic shock (secondary to ST-elevation myocardial infarction (STEMI)) criteria for cardiogenic shock are sustained hypotension (systolic blood pressure $<90 \mathrm{~mm} \mathrm{Hg}$ for $\geq 30$ $\mathrm{min})$ and a reduced cardiac index $\left(<2.2 \mathrm{~L} / \mathrm{min} / \mathrm{m}^{2}\right)$ in the presence of normal or elevated pulmonary capillary wedge pressure $(>15 \mathrm{~mm} \mathrm{Hg})$ or right ventricular end-diastolic pressure (RVEDP) (>10 mm Hg) [3].

Exclusion Criteria: patient with non ST segment elevation MI, Patients were on herbal medication or steroid treatment up to six months prior to the admission; patients with: history of hypothalamus-pituitary, adrenal dysfunction, liver diseases (ALT $\geq$ twice normal upper limit), systemic inflammatory response syndrome (SIRS; temperature $\geq 38^{\circ} \mathrm{C}$ or $\leq 36^{\circ} \mathrm{C}$, heart rate $>90$ beats $/ \mathrm{min}$, respiratory rate $\geq 20$ breaths $/ \mathrm{min}, \mathrm{PaCO} 2 \leq 32 \mathrm{~mm} \mathrm{Hg}$, white blood cell count $\geq$ $12,000 / \mu \mathrm{L}$ or $\leq 4000 / \mu \mathrm{L}$ or $>10 \%$ immature forms) basal cortisol and ACTH level were measured for all included patients immediately before a standard-dose (250 $\mu \mathrm{g})$ ACTH stimulation test (SST) and 60 minutes after SST $\Delta$ max is defined as the difference between the maximal value after the test and basal level of serum cortisol [3].

All patients were also subjected for:

Serial ECG and cardiac enzyme and echocardiography Routine laboratory investigations including $\mathrm{CBC}$, coagulation profile, and lipid profile Kidney function tests, liver function tests, arterial blood gases and serum lactate Routine calculation of the APACHYII score was calculated in the first 24 hours [4], Figure 1. 


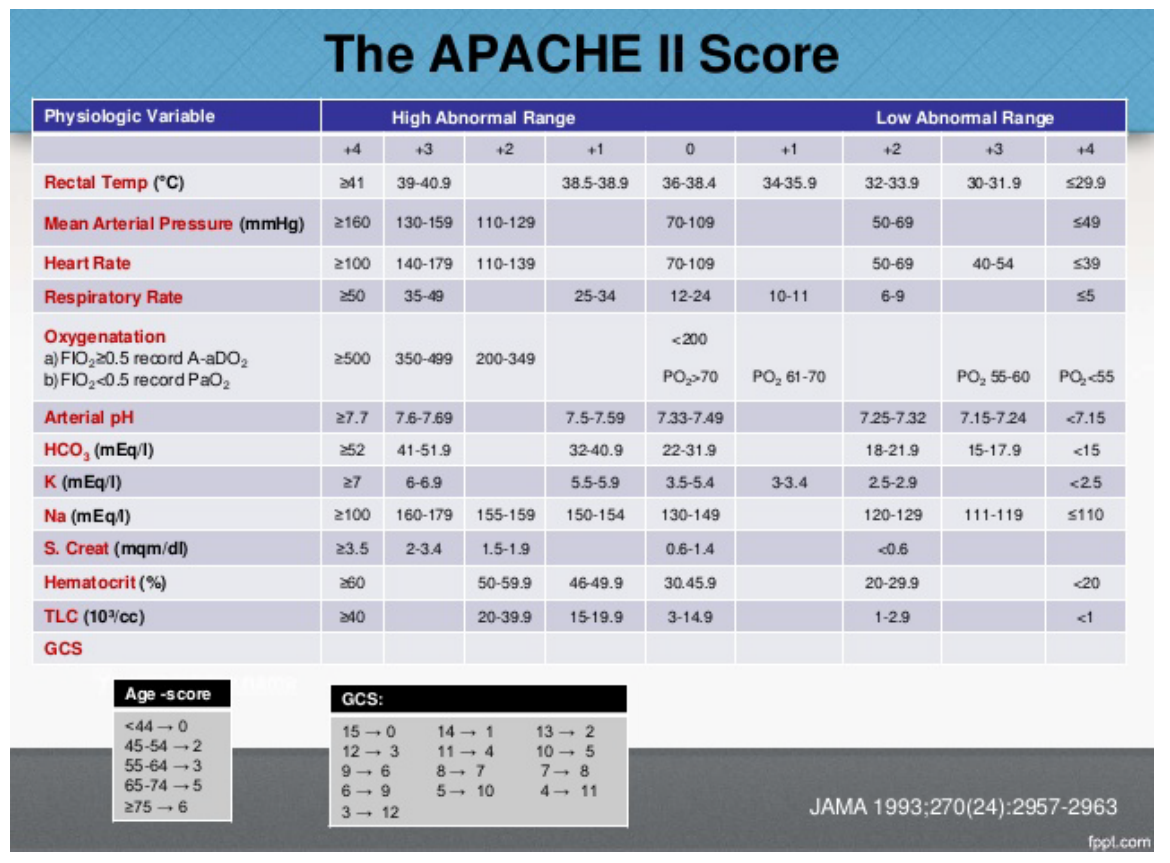

Figure 1. Parameters of APACHE II score.

Vasopressor score: calculated by the sum of the doses of adrenaline, noradrenaline, dopamine, dobutamine, milrinone, and vasopressin of the patients within the ICU stay. Overall VIS values were obtained by using the mean value of each agent.

\section{Statistical analysis:}

All collected questionnaires were revised for completeness and accuracy. Pre-coded data were collected and verified prior to analysis, statistical analyses were performed using SPSS software for windows, version 15.0 (SPSS Inc., Chicago IL, USA).

$\mathrm{P}$ value less than 0.05 was considered of statistically significance. A multiple regression model was built to identify potential significant predictors of mortality (SPSS Inc., Chicago, IL, USA).

\section{Results}

Demographic data; the included patients were $60.1 \pm 15.5$ years old (56.9 - 63.4), the study comprised 52 males (57.8\%).

\section{1) Descriptive data:}

The mean APACHE II for included patients was $80.8 \pm 17.1$, The mean LVEF was $32.2 \% \pm 6.9 \%$, The mean Fluid balance day $1685.2 \pm 914.5 \mathrm{ml} /$ day (+ve balance), the mean ACTH baseline ng/L $40.1 \pm 20.4$, The mean Total cortisol bl $\mathrm{ug} / \mathrm{dl}$ was $37.8 \pm 14.2$, the mean TC 60 min post SST was $48.9 \pm 12.9$, the mean $\Delta \max$ TC was $11.1 \pm 4.9$, the mean Steroid replacement was needed in 12 patients (13.3\%), the mean Lactate was $7.3 \pm 2.8$, the mean Arterial PH was $7.3 \pm 0.1$, the mean PO2/Fio2 was $174.5 \pm 57.8$, MAP was $57.9 \pm 5.3 \mathrm{mmhg}$, the mean HR was $102.1 \pm 19.2 \mathrm{beat} /$ minute, the mean BMI was $31.1 \pm 4.7$, the mean troponin was 
$50.0 \pm 27.7 \mathrm{ng} / \mathrm{ml}$, the mean serum creatinine was $5.0 \pm 18.1$, INTRA-aortic balloon counterpulsation30 (33.3\%), cardiac arrest occurred for 45 patients $(50.0 \%)$ and 42 patients died (Mortality 46.7\%) Table 1.

\section{2) Co-relative data:}

Baseline ACTH and total cortisol showed positive correlation to clinical severity scores (APACHE II and Lactate). They were also positively correlated to LVEF as well as vasoactive inotrope score as shown in table, all with significant $\mathrm{P}$ value (0.000) Table 2.

\section{3) Comparison between survivors and non-survivors: Table 3}

The mean age of survived patients was $51.3 \pm 12.1$ years while it was $68.9 \pm$ 13.5 years in survivors, APACHE II was higher in non-survivors (93.9 \pm 7.0 vs $67.8 \pm 14.0)$. LVEF was lower in non survivors $(26.4 \pm 4.6$ vs $38.0 \pm 2.5)$ with significant $\mathrm{P}$ value 0.000 .

Baseline ACTH was significantly lower in survivors $(28.1 \pm 9$ vs $952.0 \pm 21.3)$ p value: 0.000 .

Baseline serum cortisol level was significantly lower in survivors $30.6 \pm 6.1$ vs $45.0 \pm 16.3)$ p value: 0.000 .

TC 60 min post SST was significantly lower in survivors $44.3 \pm 5.4$ vs $53.5 \pm 9$ than non survivors $\mathrm{p}$ value 0.001 but $\triangle \mathrm{Max}$ TC (difference of cortisol level before and after SST) $(13.8 \pm 3.8$ vs $8.5 \pm 4.4)$ p value 0.000 .

Serum lactate level was lower in survivors with significance: $\mathrm{p}$ value: 0.000 .

Table 1. The baseline characteristics of the study group.

\begin{tabular}{|c|c|c|}
\hline & Mean \pm SD & Confidence interval 95\% \\
\hline Age & & $56.9-63.4$ \\
\hline APACHE II & $80.8 \pm 17.1$ & $77.3-84.4$ \\
\hline LVEF\% & $32.2 \pm 6.9$ & $30.8-33.7$ \\
\hline ACTH baseline ng/L & $40.1 \pm 20.4$ & $35.8-44.3$ \\
\hline Total cortisol bl ug/dl & $37.8 \pm 14.2$ & $34.8-40.7$ \\
\hline TC 60 min post SST & $48.9 \pm 12.9$ & $46.2-51.6$ \\
\hline$\Delta \max \mathrm{TC}$ & $11.1 \pm 4.9$ & $10.1-12.2$ \\
\hline Steroid replacement & \multicolumn{2}{|c|}{$12(13.3 \%)$} \\
\hline Lactate & $7.3 \pm 2.8$ & $6.8-7.9$ \\
\hline Arterial PH & $7.3 \pm 0.1$ & $7.2-7.3$ \\
\hline $\mathrm{PO} 2 / \mathrm{Fio} 2$ & $174.5 \pm 57.8$ & $162.4-186.6$ \\
\hline MAP & $57.9 \pm 5.3$ & $56.8-59.0$ \\
\hline HR & $102.1 \pm 19.2$ & $98.0-106.1$ \\
\hline Troponin peak ng/ml & $50.0 \pm 27.7$ & $44.2-55.8$ \\
\hline Creatinine & $5.0 \pm 18.1$ & $1.2-8.8$ \\
\hline Intra-aortic balloon counter pulsation & \multicolumn{2}{|c|}{$30(33.3 \%)$} \\
\hline Cardiac arrest & \multicolumn{2}{|c|}{$42(46.7 \%)$} \\
\hline Mortality & \multicolumn{2}{|c|}{$45(50.0 \%)$} \\
\hline
\end{tabular}


Table 2. Correlations of ACTH and total cortisol level.

\begin{tabular}{cccc}
\hline & & Baseline ACTH & Total cortisol \\
\hline \multirow{2}{*}{ APACHE II } & r value & 0.691 & 0.583 \\
& p value & 0.000 & 0.000 \\
Lactate & r value & 0.713 & 0.556 \\
& p value & 0.000 & 0.000 \\
Peak troponin & r value & 0.779 & 0.566 \\
& p value & 0.000 & 0.000 \\
LVEF\% & r value & -0.750 & -0.764 \\
& p value & 0.000 & 0.000 \\
& r value & 0.585 & 0.462 \\
Cumulative vasopressor index & p value & 0.000 & 0.000 \\
\hline
\end{tabular}

Table 3. Comparison between survivors and non-survivors.

\begin{tabular}{|c|c|c|c|}
\hline & $\begin{array}{c}\text { Survivors } \\
\text { No.48 }\end{array}$ & $\begin{array}{c}\text { Non-survivors } \\
\text { No.42 }\end{array}$ & $P$ value \\
\hline Age & $51.3 \pm 12.1$ & $68.9 \pm 13.5$ & 0.000 \\
\hline Gender (Male) & $28(62.2 \%)$ & $24(53.3 \%)$ & 0.261 \\
\hline APACHE II & $67.8 \pm 14.0$ & $93.9 \pm 7.0$ & 0.000 \\
\hline LVEF\% & $38.0 \pm 2.5$ & $26.4 \pm 4.6$ & 0.000 \\
\hline Fluid balance day 1 & $-89.3 \pm 285.4$ & $1459.8 \pm 618.9$ & 0.000 \\
\hline ACTH baseline ng/L & $28.1 \pm 9.9$ & $52.0 \pm 21.3$ & 0.000 \\
\hline total cortisol bl ug/dl & $30.6 \pm 6.1$ & $45.0 \pm 16.3$ & 0.000 \\
\hline TC 60 min post SST & $44.3 \pm 5.4$ & $53.5 \pm 16.2$ & 0.001 \\
\hline$\Delta \max \mathrm{TC}$ & $13.8 \pm 3.8$ & $8.5 \pm 4.4$ & 0.000 \\
\hline Lactate & $4.9 \pm 1.8$ & $9.7 \pm 0.6$ & 0.000 \\
\hline Arterial PH & $7.3 \pm 0.1$ & $7.2 \pm 0.0$ & 0.000 \\
\hline $\mathrm{PO} 2 / \mathrm{Fio} 2$ & $220.6 \pm 32.8$ & $128.5 \pm 36.7$ & 0.000 \\
\hline MAP & $62.3 \pm 3.1$ & $53.5 \pm 2.7$ & 0.000 \\
\hline HR & $96.6 \pm 7.9$ & $107.5 \pm 25.0$ & 0.008 \\
\hline BMI & $29.9 \pm 4.5$ & $32.3 \pm 4.7$ & 0.012 \\
\hline Troponin peak ng/ml & $27.1 \pm 17.4$ & $73.0 \pm 13.1$ & 0.000 \\
\hline Creatinine & $8.0 \pm 25.4$ & $1.9 \pm 0.2$ & 0.114 \\
\hline Epinephrine & $0.1 \pm 0.1$ & $0.3 \pm 0.0$ & 0.000 \\
\hline Norepinephrine & $0.1 \pm 0.2$ & $0.3 \pm 0.0$ & 0.000 \\
\hline Dopamine & $4.2 \pm 1.8$ & $10.0 \pm 0.0$ & 0.000 \\
\hline Dobutamine & $0.7 \pm 1.7$ & $6.7 \pm 3.5$ & 0.000 \\
\hline Inotrope score & $11.5 \pm 11.7$ & $46.7 \pm 3.5$ & 0.000 \\
\hline Vasoactive inotropic score & $23.5 \pm 32.9$ & $76.7 \pm 3.5$ & 0.000 \\
\hline Cumulative vasopressor index & $4.8 \pm 2.6$ & $10.0 \pm 0.0$ & 0.000 \\
\hline IABP & $6(13.3 \%)$ & $24(53.3 \%)$ & 0.000 \\
\hline Cardiac arrest & $9(20.0 \%)$ & $33(73.3 \%)$ & 0.000 \\
\hline
\end{tabular}


$\mathrm{PH}$ was higher in survivors with significant $\mathrm{p}$ value; 0.000 .

The Oxygenation index was higher in $s$ in survivors with significant $p$ value; 0.000 .

The MAP was higher in survivors with significant $\mathrm{p}$ value; 0.000 .

The HR was lower in survivors with significant $p$ value; 0.000 .

The BMI was lower in survivors with significant $\mathrm{p}$ value; 0.008 .

The peak troponin level was lower in survivors with significant $\mathrm{p}$ value; 0.000 .

The vasoactive score was lower in survivors with significant $\mathrm{p}$ value; 0.000 .

6 patients (13.3\% of the survivors) required IABP while it inserted for 24 patients (53.3\% only of non survivors) with significant $\mathrm{p}$ value; 0.000 .

9 patients (20.0\% of survivors) suffered from cardiac arrest while 33 patients (73.3\% of non survivors) suffered from cardiac arrest before death p value 0.000 .

4) The ROC curve of the peak troponin, basal cortisol and ACTH level: Figure 2 and Table 4

The area under the curve for peak troponin was 0.956 and cut off level was 50 $\mu \mathrm{g} / \mathrm{mL}$ with sensitivity and specificity of $93.3 \%$. The positive predictive value is $93.3 \%$ and the negative predictive value is $93.3 \%$.

The area under the curve for ACTH was 0.811 and cut off level was $35 \mu \mathrm{g} / \mathrm{mL}$ with sensitivity and specificity of $73.3 \%$. The positive predictive value is $73.3 \%$ and the negative predictive value is $73.3 \%$.

The area under the curve for total cortisol was 0.731 and cut off level was 35 $\mu \mathrm{g} / \mathrm{mL}$ with sensitivity $64.3 \%$ and specificity of $86.7 \%$. The positive predictive value is $81.7 \%$ and the negative predictive value is $72.2 \%$ (Table 4 ).

5) The ROC curve of the cumulative vasopressor index, inotropic score and vasoactive inotropic score Figure 3 and Table 5:

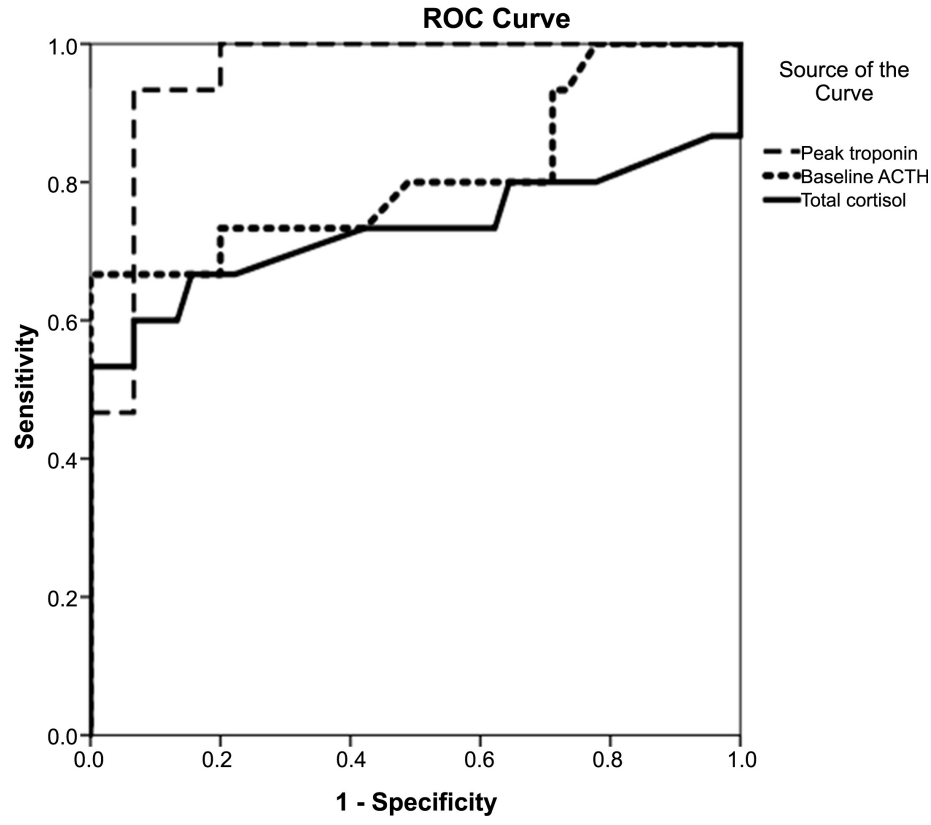

Figure 2. The ROC curve of peak troponin, basal cortisol and ACTH level in the study groups. 
Table 4. Data of the ROC curve of peak troponin, ACTH and total cortisol in the study group.

\begin{tabular}{cccccccc}
\hline & Area & p value & Cut-off & Sensitivity & Specificity & PPV & NPV \\
\hline Peak troponin & 0.956 & 0.000 & 50.0 & $93.3 \%$ & $93.3 \%$ & $93.3 \%$ & $93.3 \%$ \\
ACTH & 0.811 & 0.000 & 35.0 & $73.3 \%$ & $73.3 \%$ & $73.3 \%$ & $73.3 \%$ \\
Total cortisol & 0.731 & 0.000 & 35.0 & $64.3 \%$ & $86.7 \%$ & $81.8 \%$ & $72.2 \%$ \\
\hline
\end{tabular}

Table 5. Data of the ROC curve of inotrope score, ACTH and total cortisol in the study group.

\begin{tabular}{cccccccc}
\hline & Area & p value & Cut-off & Sensitivity & Specificity & PPV & NPV \\
\hline Inotrope score & 0.978 & 0.000 & 35 & $100.0 \%$ & $93.3 \%$ & $93.8 \%$ & $100.0 \%$ \\
VIS & 0.996 & 0.000 & 65 & $100.0 \%$ & $93.3 \%$ & $93.8 \%$ & $100.0 \%$ \\
\hline
\end{tabular}

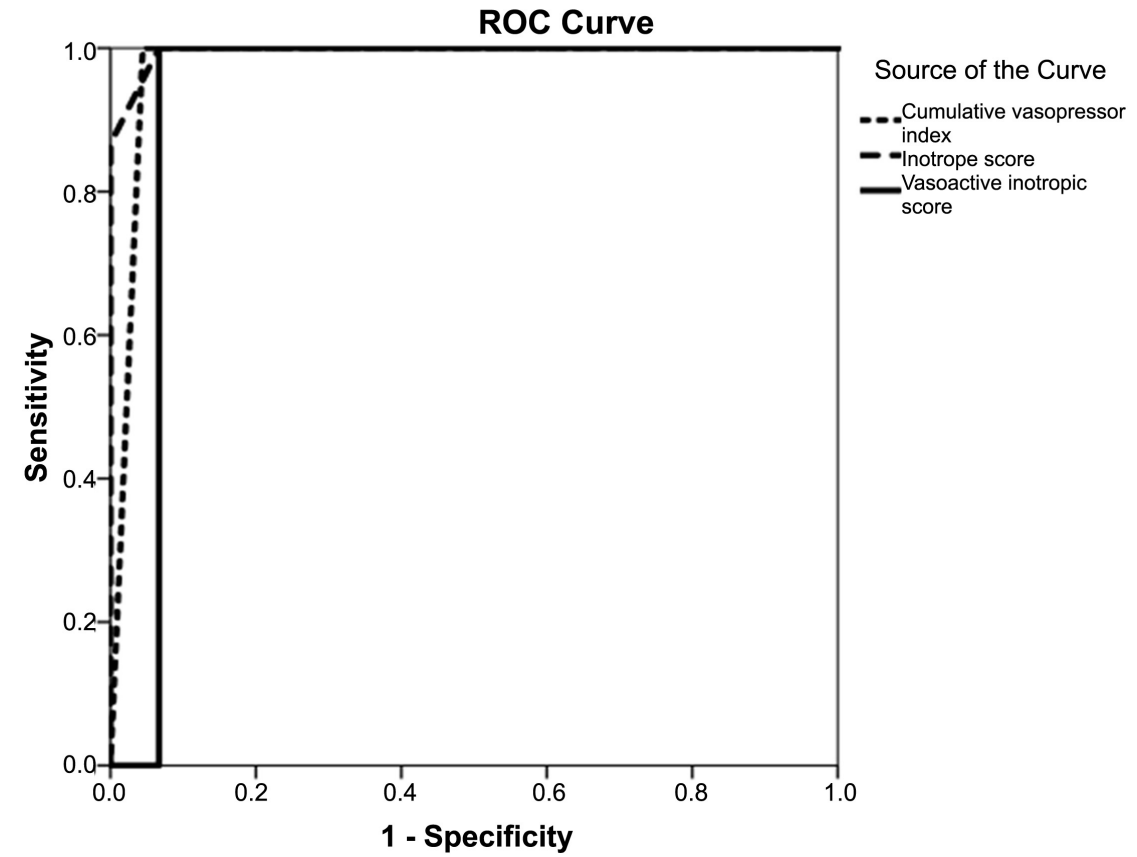

Figure 3. The ROC curve of the cumulative vasopressor index, inotropic score and vasoactive inotropic score.

The area under the curve for inotrope score was 0.978 and cut off level was 35 with sensitivity $100 \%$ and specificity of $93.3 \%$. The positive predictive value is $93.8 \%$ and the negative predictive value is $100 \%$

The area under the curve for vasopressor index score was 0.996 and cut off level was 65 with sensitivity $100 \%$ and specificity of $93.3 \%$. The positive predictive value is $93.8 \%$ and the negative predictive value is $100 \%$ (Table 5).

\section{Discussion}

The objective of this study was to determine the prevalence of relative adrenal insufficiency by using SST in patients with cardiogenic shock complicating acute 
ST-segment elevation MI.

There was a higher prevalence of cardiogenic shock in males this may be due to The higher prevalence of myocardial infarction (MI) in men in all age-specific groups than women as documented by Joshua et al. 2018 [5].

In this study serum total cortisol level was measured on admission and short stimulation test was done by injection of 250 micrograms ACTH (Synacthen) and another sample of cortisol level was assessed 60 minutes later. The baseline TC was $37.8 \pm 14.2 \mu \mathrm{g} / \mathrm{dL}$ basal ACTH was $40.1 \pm 20.4 \mathrm{ng} / \mathrm{L}$ and cortisol level after 60 minutes was $48.9 \pm 12.9 \mu \mathrm{g} / \mathrm{dL}$, these results were near to the results of Tol M.M. et al. who found baseline total cortisol level $34 \mu \mathrm{g} / \mathrm{dL}$ and $45 \mu \mathrm{g} / \mathrm{dL}$ [5] [6].

The study concluded that the baseline total cortisol and ACTH were correlated with APACHE II score, serum lactate, peak troponin, LVEF, inotropic index and cumulative vasoactive index with significant $\mathrm{P}$ value, This results are matched with the results of Ming-Hung Tsa [7] who found that the baseline total cortisol was correlated with APACHE II score and lactate level in patients diagnosed to have septic shock, Critical illness is accompanied by the activation of the hypothalamic-pituitary-adrenal axis, which is highlighted by increased serum corticotropin and cortisol levels [7] [8]. The activation of the hypothalamic-pituitary-adrenal axis is a crucial component of the host's adaptation to severe stress. Cortisol is essential for the normal function of the immune system and various cellular functions. Recently, the concept of critical illness-related corticosteroid insufficiency (CIRCI) has been put forward to describe a subnormal adrenal response to adrenocorticotropin in severe illness, in which the cortisol levels, although high in terms of absolute value, are inadequate to control the inflammatory situation [8]. The short corticotropin stimulation test (SST) is most commonly used to evaluate the appropriateness of the adrenal response in this setting [9].

In this study, APACHE II score, serum lactate, total cortisol level, peak troponin and delta $\max [\Delta \max ]$ in cortisol levels between T0 and the highest value at T60 were associated with poor prognosis and higher mortality Maneesha, M. et al. [5] performed a short corticotropin stimulation test in 35 patients with cardiogenic shock after AMI by injecting of $250 \mu \mathrm{g}$ of tetracosactrin (Synacthen) intravenously. Blood samples were obtained at baseline (T0) before and at 60 (T60) minutes after the test to determine total plasma cortisol (TC) and free cortisol concentrations. The primary outcome measure was in-hospital mortality and its association with T0 TC and maximum response to corticotropin (maximum difference $[\Delta \max ]$ in cortisol levels between $\mathrm{T} 0$ and its value at T60). The in-hospital mortality was $37 \%$, and there was some evidence of an increased mortality in patients with T0 TC concentrations more than $34 \mu \mathrm{g} / \mathrm{dL}(\mathrm{p}=0.07)$. Maximum difference by was not an independent predictor of death. Patients with a T0 TC less than $34 \mu \mathrm{g} / \mathrm{dL}$ or with $\Delta$ max greater than $9 \mu \mathrm{g} / \mathrm{dL}$ had the most favorable survival.

In tour study the in hospital mortality was $50 \%$ the higher mortality in our 
study may be due to larger sample and more extensive myocardial injury as manifested by low ejection fraction.

The study also concluded that cardiac troponin had the highest sensitivity and specificity for diagnosis of cardiogenic shock, Area under the curve is 0.978. Sensitivity is $100 \%$ and specificity is $93.3 \%$, the same results were also concluded by a study done by Dong-Ryeol Ryu [10] who stated that Receiver operator characteristic (ROC) curve of cardiac troponin $\mathrm{T}(\mathrm{cTnT}$ ) for diagnosing acute myocardial infarction. The area under the curve (AUC) was 0.98 (p $<0.001 ; 95 \% \mathrm{CI}$, 0.95 - 1.00). The cTnT value of $0.35 \mathrm{ng} / \mathrm{mL}$ offers the best sensitivity and specificity; the sensitivity was 0.95 and the specificity was 0.97 .

The ROC for ACTH and baseline cortisol levels were 0.811 and 0.731 respectively, There were various criteria used to diagnose adrenal insufficiency in previous studies. However, those studies were conducted in critically ill patients, and none has been done on cardiogenic shock patients so far. In this respect, the cut-off cortisol level which indicates adrenal insufficiency in severely-ill patients is still debatable [11].

Cardiogenic shock shares immune mechanisms with septic shock. Low-flow state and general inflammation causes endothelial injury and organ dysfunctions Inflammatory mediators, oxidant stress, and causes vasodilatation and low general resistance determined in several patients with cardiogenic shock complicating acute MI. Excessive oxidative stress as in septic shock has been known to suppress steroidogenesis in adrenal glands this might justify why the adrenal responsiveness is altered within the majority of patients with severe cardiogenic shock [12].

\section{Conclusion}

A high baseline plasma TC was associated with increased mortality in patients with cardiogenic shock post-AMI. Patients with lower baseline TC, but with a better adrenal response, appeared to have a survival benefit.

\section{Conflicts of Interest}

The authors declare no conflicts of interest regarding the publication of this paper.

\section{References}

[1] Boonen, E., Vervenne, H., Meersseman, P., Andrew, R., Mortier, L., Declercq, P.E., Vanwijngaerden, Y.M., Spriet, I., Wouters, P.J., Vander Perre, S., et al. (2013) Reduced Cortisol Metabolism during Critical Illness. The New England Journal of Medicine, 368, 1477-1488. https://doi.org/10.1056/NEJMoa1214969

[2] Annane, D., Sébille, V., Troché, G., Raphaël, J.C., Gajdos, P. and Bellissant, E. (2000) A 3-Level Prognostic Classification in Septic Shock Based on Cortisol Levels and Cortisol Response to Corticotropin. JAMA, 283, 1038-1045. https://doi.org/10.1001/jama.283.8.1038

[3] Babaev, A., Frederick, P.D., Pasta, D.J., et al. (2005) Trends in Management and 
Outcomes of Patients with Acute Myocardial Infarction Complicated by Cardiogenic Shock. JAMA, 294, 448-454. https://doi.org/10.1001/jama.294.4.448

[4] Knaus, W.A., Draper, E.A., Wagner, D.P. and Zimmerman, J.E. (1985) APACHE II: A Severity of Disease Classification System. Critical Care Medicine, 13, 818-829. https://doi.org/10.1097/00003246-198510000-00009

[5] Tol, M.M., Shekar, K., Barnett, A.G., McGree, J., McWhinney, B.C., Ziegenfuss, M., Ungerer, J.P. and Fraser, J.F. (2014) A Preliminary Investigation into Adrenal Responsiveness and Outcomes in Patients with Cardiogenic Shock after Acute Myocardial Infarction. Journal of Critical Care, 29, 470.e1-470.e6.

https://doi.org/10.1016/j.jcrc.2014.01.020

[6] Jayaraj, J.C., Davatyan, K., Subramanian, S.S. and Priya, J. (2018) Epidemiology of Myocardial Infarction. IntechOpen, London.

https://doi.org/10.5772/intechopen.74768

[7] Tsai, M.-H. (2009) Critical Illness-Related Corticosteroid Insufficiency in Patients with Severe Acute Biliary Pancreatitis: A Prospective Cohort Study. Critical Care, 13, R123. https://doi.org/10.1186/cc7978

[8] Cooper, M.S. and Stewart, P.M. (2003) Corticosteroid Insufficiency in Acutelyill Patients. The New England Journal of Medicine, 348, 727-734.

https://doi.org/10.1056/NEJMra020529

[9] Jurney, T.H., Cockrell, J.L., Lindberg, J.S., Lamiell, J.M. and Wade, C.E. (1987) Spectrum of Serum Cortisol Response to ACTH in ICU Patients. Correlation with Degree of Illness and Mortality. Chest, 92, 292-295.

https://doi.org/10.1378/chest.92.2.292

[10] Ryu, D.-R. and Chung, J.H. (2011) Yonsei Medical Journal, 52, 595-602.

[11] Harry, R., Auzinger, G. and Wendon, J. (2002) The Clinical Importance of Adrenal Insufficiency in Acute Hepatic Dysfunction. Hepatology, 36, 395-402.

https://doi.org/10.1053/jhep.2002.34514

[12] Marik, P.E., Pastores, S.M., Annane, D., Meduri, G.U., Sprung, C.L., Arlt, W., Keh, D., Briegel, J., Beishuizen, A., Dimopoulou, I., Tsagarakis, S., Singer, M., Chrousos, G.P., Zaloga, G., Bokhari, F. and Vogeser, M. (2008) Recommendations for the Diagnosis and Management of Corticosteroid Insufficiency in Critically Ill Adult Patients: Consensus Statements from an International Task Force by the American College of Critical Care Medicine. Critical Care Medicine, 36, 1937-1949. https://doi.org/10.1097/CCM.0b013e31817603ba 